\title{
Q ualidade da água de um córrego sob influência de efluente tratado de abate bovino
}

\author{
Michael S. Thebaldi ${ }^{1}$, Delvio Sandri' ${ }^{2}$ Alberto B. Felisberto ${ }^{2}$, \\ Marco S. da Rocha ${ }^{2} \&$ Sebastião A. N eto ${ }^{2}$
}

\begin{abstract}
RESU MO
As agroindústrias figuram entre as maiores fontes poluidoras das águas no Brasil, em função da grande quantidade de resíduos produzidos, contendo substâncias orgânicas, nutrientes, sólidos, óleos e graxas. 0 objetivo deste trabalho foi analisar o efeito do lançamento de efluente de abate de bovinos sobre a qualidade da água do Córrego Jurubatuba, em Anápolis, GO. As amostras de efluente e a água foram obtidas em seis diferentes dias e em quatro posições, em relação ao ponto de lançamento: P1 - na saída do efluente tratado, antes do lançamento no córrego; P2 - 50 m à montante do ponto de descarga; P3 $50 \mathrm{~m}$ à jusante do ponto de descarga e P4 - $120 \mathrm{~m}$ à jusante do ponto de descarga. Analisaram-se as concentrações de OD, DBO, DQO, amônia, nitrito e nitrato. Os valores de DBO em todos os pontos de coleta no Córrego Jurubatuba foram superiores aos padrões descritos na Resolução do CO NAMA no $357 / 2005$ para cursos de água da classe 2. O lançamento de efluente no Córrego Jurubatuba elevou os valores de DBO e DQO no ponto P3, enquanto no ponto P4 foi semelhante aos valores obtidos antes do lançamento de efluente. As concentrações de oxigênio dissolvido, amônia, nitrito e nitrato, não sofreram al terações significativas no córrego.
\end{abstract}

Palavras-chave: DBO, autodepuração, corpo hídrico receptor

\section{Water quality of a stream under influence of cattle slaughter treated effluent}

\begin{abstract}
Agroindustrial systems are among the largest sources of water pollution in Brazil, due to the large amount of waste produced, containing organic substances, nutrients, solids, oils and fats. This study aimed to analyze the effect of release of cattle slaughter treated effluent on the water quality of the Jurubatuba Stream in the municipality of Anápolis, GO. The effluent and stream water samples were obtained at six different days and at four positions in relation to the point of discharge: P1 - the discharge of the treated wastewater, before launching it into the stream; P2 - upstream, $50 \mathrm{~m}$ away from the discharge point; P3 - downstream, $50 \mathrm{~m}$ away from the discharge point; and P4 - downstream, $120 \mathrm{~m}$ away from the discharge point. The concentrations of DO, BOD, COD, ammonia, nitrite and nitrate were analyzed. The BO D values at all samphing points in the Jurubatuba Stream were higher than the described standards of CONAMA Resolution $n^{\circ}$. 357/2005 for class 2 water bodies. The effluent launch in Jurubatuba Stream increased values of $B O D$ and $C O D$ at point $P 3$, while at point P4 values were similar to those obtained upstream the effluent release (P2). The concentrations of DO, ammonia, nitrite and nitrate did not change significantly in the stream.
\end{abstract}

Key words: BOD, self-purification, receiving water body 


\section{INTRODUÇÃO}

A água é essencial aos seres vivos, à produção agrícola, uso doméstico e aos processos industriais (Hu, 2009). As agroindústrias estão entre as maiores fontes poluidoras no Brasil, particularmente em função das grandes quantidades de resíduos ricos em substâncias orgânicas, nutrientes (sobretudo nitrogênio e fósforo), sólidos, óleos e graxas. Nesta categoria, matadouros e indústrias de processamento de carne são conhecidos pelo alto potencial poluidor (Mees et al., 2009).

$\mathrm{O}$ efluente dos matadouros possui uma elevada vazão e grande carga de sólidos em suspensão, nitrogênio orgânico e uma DBO de $4.200 \mathrm{mg} \mathrm{L}^{-1}$ em média (Aguilar, 2002), dependendo do reaproveitamento ou do tratamento do efluente. Devido à sua constituição, esses despejos são altamente putrescíveis, iniciando sua decomposição em poucas horas e formando gases malcheirosos, que tornam difícil a respiração nos arredores desses estabelecimentos (Pacheco \& Wolff, 2004).

Para que esse tipo de efluente atinja o padrão requerido para ser lançado em corpos hídricos, deve-se proceder ao seu adequado tratamento. A evolução dos sistemas de tratamento de efluentes agroindustriais tem disponibilizado tecnologias eficientes para a remoção da carga orgânica (Naime \& Garcia, 2005). Segundo Sousa et al. (2006) a utilização de lagoas de estabilização figuram entre os melhores métodos de tratamento de efluentes, principalmente quando esse efluente possui o objetivo de ser aplicado na agricultura.

Rodrigues et al. (2010) analisando o efluente de suinocultura tratado em reator anaeróbio de fluxo ascendente em manta de lodo (Upflow anaerobic sludge blanket, ou UASB) e previamente decantado, obtiveram eficiência de remoção superior a $90 \%$ em relação ao afluente recebido pelo reator. Rodrigues et al. (2009) avaliaram o mesmo sistema descrito anteriormente, porém acrescido de uma lagoa de polimento como última unidade de tratamento, observando uma redução ainda maior da DBO, o que ressalta a importância de um tratamento adequado às águas residuárias.

As águas residuárias devem ser lançadas em corpos hídricos volumosos e perenes, que podem autodepurar a carga recebida sem maiores prejuízos, porém vários corpos hídricos que margeiam as cidades brasileiras vêm recebendo constantes cargas de material orgânico e mineral, superando sua capacidade de autodepuração (Leite et al., 2005). Isto faz com que as águas receptoras se tornem impróprias a vários tipos de uso (abastecimento doméstico, comercial ou agrícola, recreação, etc.). Em vista disso, é muito importante considerar a capacidade de assimilação dos rios e impedir o lançamento de efluentes tratados em vazão superior à que o corpo d'água possa suportar.

Despejos de água residuária são o maior componente da poluição aquática, contribuem para aumentar a demanda de oxigênio (DBO) e a carga de nutrientes de corpos d'água, causam impactos negativos ao ambiente e levam à desestabilização de ecossistemas aquáticos (Morrison et al., 2001). A qualidade da água disponível e acessível, tem grande impacto no padrão de vida e bem-estar da população (Odjadjare \& Okoh, 2010).
Alguns desses impactos negativos podem ser observados na Bacia do Córrego Lagoinha, onde se encontra o Córrego Jurubatuba, localizada na Área de Proteção Ambiental (APA) do Ribeirão João Leite. Essa APA foi implantada em 2002 e enfrenta uma série de problemas oriundos da ocupação desordenada, muito anterior à data da sua criação. Já é possível identificar na bacia do Córrego Lagoinha, que ainda é mais rural do que urbana, problemas de erosão e de assoreamento semelhantes aos existentes em bacias urbanas com características geológicas, geomorfológicas e pedológicas similares (Santos \& Lopes, 2007).

Na região de despejo do efluente proveniente do frigorífico estudado, se encontram diversas pequenas propriedades rurais instaladas nas margens do Córrego Jurubatuba voltadas principalmente à produção de hortaliças. Nas áreas irrigadas dessas propriedades se utiliza, sobretudo, a aspersão convencional. Se este tipo de sistema de irrigação for utilizado com água poluída, principalmente em hortaliças folhosas, pode causar problemas de contaminação e aumentar o risco de doenças.

Em vista do exposto e de poucas informações presentes na literatura sobre o tratamento e lançamento de efluente de abate bovino em corpos hídricos, esse trabalho objetivou analisar o efeito do lançamento de efluente de abate de bovinos sobre a qualidade da água do Córrego Jurubatuba.

\section{Material e MÉTOdos}

Para investigar uma possível mudança na qualidade da água do Córrego Jurubatuba em função do lançamento do efluente tratado, amostras de água foram coletadas em quatro pontos, como mostrado na Figura 1: P1 (descarga do efluente tratado antes do lançamento no córrego); P2 (50 m à montante do ponto de descarga), P3 (50 m à jusante do ponto de descarga) e P4 (120 m à jusante do ponto de descarga), com seis repetições (coletas), realizadas nos dias 10, 17, 24 e 31 de agosto e 14 e 21 de setembro, entre 7 e $8 \mathrm{~h}$.

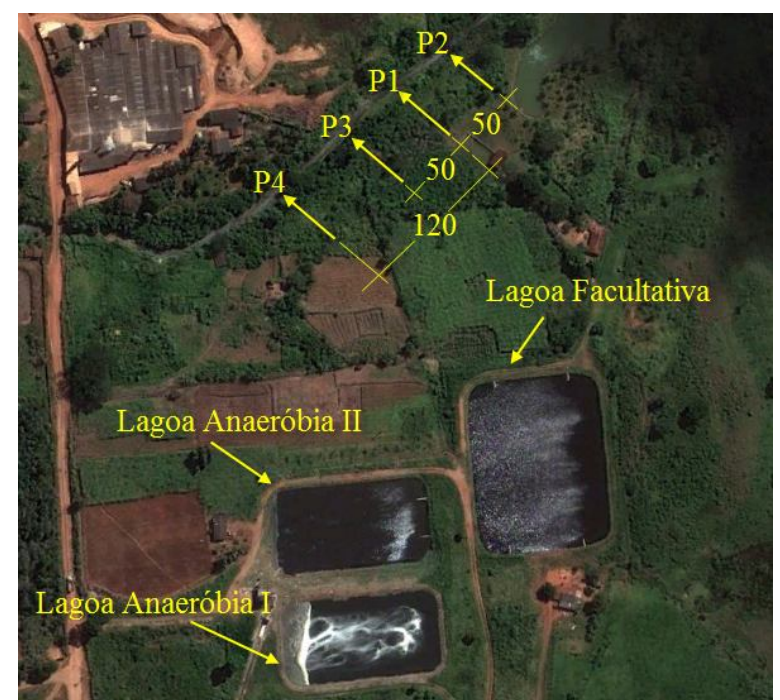

Figura 1. Localização dos pontos de coleta de amostras de água para análise 
O efluente tratado utilizado no estudo provinha da estação de tratamento de esgotos (ETE) de um frigorífico localizado no município de Anápolis, GO. A ETE se situa nas coordenadas geográficas $16^{\circ} 19^{\prime} 17^{\prime}$ ' S e 48 59' 33" W e é constituída de três lagoas de estabilização em série, das quais duas anaeróbias com volume útil de 9867,90 e 8107,44 m³ e uma lagoa facultativa com volume útil de $12900,00 \mathrm{~m}^{3}$. Após o tratamento, o efluente do sistema é lançado no Córrego Jurubatuba.

$\mathrm{O}$ ponto de coleta $\mathrm{P} 1$, referente à saída do efluente tratado, é composto de um tubo de PVC de $100 \mathrm{~mm}$, que conduz o efluente ao Córrego Jurubatuba (Figura 2A); já o ponto de coleta P2 (50 m à montante do ponto de descarga), é uma área do córrego bem rasa, caracterizada por grande presença de material pedregoso ao fundo que causa grande turbulência no curso de água (Figura 2B); o ponto de coleta P3 está localizado em uma área sombreada por vegetação nativa, próximo à margem do Córrego Jurubatuba. Neste ponto o fluxo de água do córrego apresenta pouca turbulência (Figura 2C). O ponto de coleta P4 (120 m à jusante do ponto de descarga) é o que apresenta maior turbulência da água, pois está localizado em uma área de redução da largura do Córrego Jurubatuba (Figura 2D). A vazão média do córrego obtida durante o período de coletas foi de $0,195 \mathrm{~m}^{3} \mathrm{~s}^{-1}$.

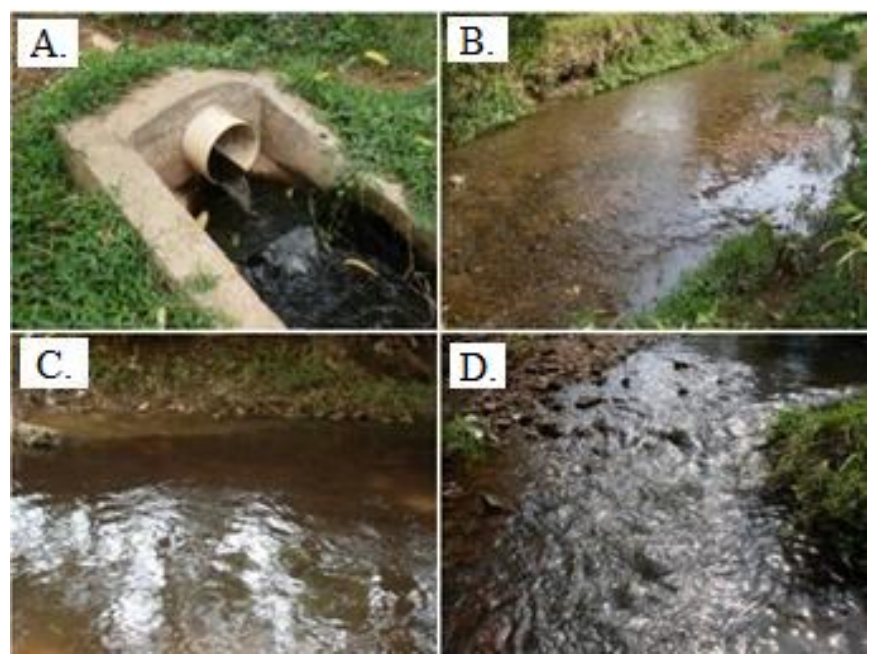

Figura 2. Pontos de coleta de efluente tratado: P1 (descarga do efluente tratado), P2 (50 m à montante do ponto de descarga), P3 (50 m à jusante do ponto de descarga) e P4 (120 m à jusante do ponto de descarga)

A Tabela 1 mostra a quantidade de cabeças de gado abatidas por semana a partir de sete dias antes do início das coletas de amostra de efluente e água. O número médio de cabeças de gado abatidas por semana no estabelecimento a partir do início de 2009 até o início do experimento foi praticamente o mesmo aos apresentados durante as amostragens.

A Figura 3 mostra o número de cabeças de gado abatidas no frigorífico em estudo, no período de 3 de agosto de 2009 a 20 de setembro de 2009.

No decorrer do experimento foram colhidos dados de precipitação através do Sistema de Meteorologia e Hidrologia do Estado de Goiás, provenientes de uma estação meteorológica automatizada instalada na cidade de Anápolis.
Tabela 1. Q uantidade de cabeças de gado abatidas por semana a partir de sete dias antes do início das coletas de amostra de efluente e água

\begin{tabular}{cccc}
\hline Intervalo de dias & $\begin{array}{c}\text { Quantidade } \\
\text { de cabeças } \\
\text { de gado } \\
\text { abatidas }\end{array}$ & $\begin{array}{c}\text { Volume } \\
\text { afluído na ETE } \\
\left(\mathbf{m}^{3}\right)\end{array}$ & $\begin{array}{c}\text { Tempo de } \\
\text { detenção } \\
\text { hidráulica } \\
\text { teórico } \\
\text { (semanas) }\end{array}$ \\
\hline 03 à 9/8/2009 & 1534 & 3835,0 & 8,05 \\
10 à 16/8/2009 & 1455 & 3637,5 & 8,49 \\
17 à 23/8/2009 & 1698 & 4245,0 & 7,27 \\
24 à 30/8/2009 & 1526 & 3815,0 & 8,09 \\
$31 / 8$ à 6/9/2009 & 1750 & 4375,0 & 7,06 \\
07 à 13/9/2009 & 1845 & 4612,5 & 6,69 \\
14 à 20/9/2009 & 2123 & 5307,5 & 5,82 \\
\hline
\end{tabular}

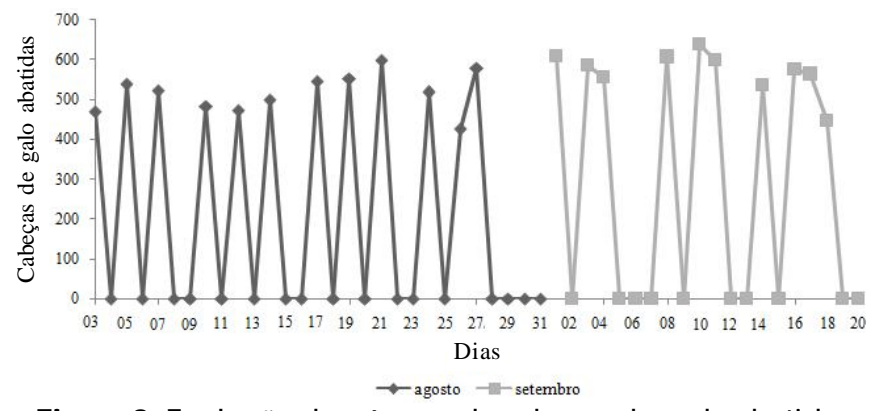

Figura 3. Evolução do número de cabeças de gado abatidas a partir de sete dias antes do início das coletas de amostra de água

No período de 9 de agosto a 20 de setembro de 2009, ocorreram precipitações apenas nos dias 23 de agosto e 20 de setembro, de $0,5 \mathrm{~mm}$ e $5,75 \mathrm{~mm}$, respectivamente.

Foram analisados os parâmetros DBO, DQO, amônia, nitrito, nitrato e o oxigênio dissolvido, obtido com oxímetro digital microprocessado modelo AT-150, marca Alfakit, com faixa de resolução de 0,01 até $50,0 \mathrm{mg} \mathrm{L}^{-1}$; as análises foram realizadas in situ.

A DBO e a DQO foram determinadas seguindo-se metodologias apresentadas em APHA (1995). Obteve-se a concentração de amônia de acordo com o procedimento descrito por Merck (1972), o nitrito foi obtido segundo o procedimento descrito por Fries (1971) e os valores de nitrato foram obtidos por meio do procedimento descrito por Fries \& Getrost (1977). Com exceção da DBO, para os demais parâmetros a concentração em $\mathrm{mg} \mathrm{L}^{-1}$ foi obtida em um fotocolorímetro de bancada, modelo Superfoto, marca Alfakit, com resolução de $0,001 \mathrm{mg} \mathrm{L}^{-1}$; para a concentração e de 0,001 para absorvância e precisão relativa de $2 \%$.

Os resultados obtidos pelas análises foram comparados aos padrões de lançamento descritos em Brasil (2005) e as concentrações dos parâmetros de qualidade da água foram comparadas pelos testes de F e Tukey a 5\% de significância e utilizados gráficos de box-plot para auxiliar a interpretação dos resultados obtidos.

\section{RESULTADOS E DISCUSSÃO}

Além de outros fatores, a qualidade do efluente tratado pode variar em função da carga orgânica dos esgotos afluentes 


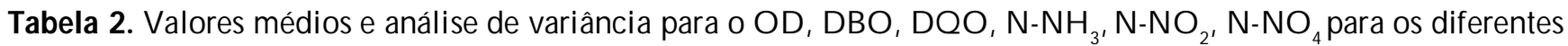
pontos de análise

\begin{tabular}{|c|c|c|c|c|c|c|c|}
\hline \multirow{2}{*}{ Parâmetro ( $\mathrm{mg} \mathrm{L}^{-1}$ ) } & \multicolumn{4}{|c|}{ Pontos de análise } & \multirow{2}{*}{ DesvPad } & \multirow{2}{*}{$\mathbf{F}$} & \multirow{2}{*}{ CV $(\%)$} \\
\hline & P1 & P2 & P3 & P4 & & & \\
\hline OD & 5,14 & 5,46 & 5,37 & 5,48 & 0,210 & $2,11 \mathrm{~ns}$ & 3,98 \\
\hline DBO & $203,41 \mathrm{~A}$ & $73,68 \mathrm{~B}$ & $126,71 \mathrm{AB}$ & $71,21 \mathrm{~B}$ & 55,610 & $7,45 *$ & 46,83 \\
\hline $\mathrm{DQO}$ & $298,69 \mathrm{~A}$ & $87,47 \mathrm{~B}$ & $167,99 A B$ & $71,15 \mathrm{~B}$ & 93,680 & $7,38 *$ & 59,93 \\
\hline $\mathrm{N}-\mathrm{NH}_{4}$ & 0,36 & 0,03 & 0,25 & 0,13 & 0,410 & $0,75 \mathrm{~ns}$ & 12,46 \\
\hline $\mathrm{N}-\mathrm{NO}_{2}$ & $0,18 \mathrm{~A}$ & $0,07 \mathrm{~B}$ & $0,09 \mathrm{~B}$ & $0,07 \mathrm{~B}$ & 0,049 & $7,22 *$ & 8,03 \\
\hline $\mathrm{N}-\mathrm{NO}_{3}$ & 0,61 & 0,75 & 0,73 & 1,11 & 0,630 & 0,72 ns & 8,16 \\
\hline
\end{tabular}

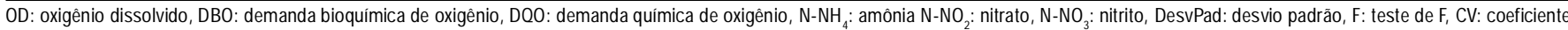
de variação, ns: não significativo; P1: descarga do efluente testado; P2: $50 \mathrm{~m}$ à montante do ponto de descarga; P3: $50 \mathrm{~m}$ à jusante do ponto de descarga; P4: $120 \mathrm{~m}$ à jusante do ponto de descarga

* Significativo pelo teste de $\mathrm{F}$ a $5 \%$ de probabilidade. Valores na linha seguidos da mesma letra maiúscula não diferem estatisticamente pelo teste de Tukey a $5 \%$ de probabilidade

à estação de tratamento, sendo esta diretamente relacionada ao fluxo de abate (animais abatidos por dia). Observou-se que durante o período de coleta de amostras de efluente, não houve grande variação no fluxo semanal de abate (Tabela 1), porém a Figura 3 mostra que não houve abates em vários dias do período analisado, fato que pode modificar a qualidade do efluente final das lagoas. Mesmo apresentando um alto tempo de detenção hidráulica em função do número de abates (Tabela 1), cargas afluentes que passem por curtos-circuitos hidráulicos na ETE promovem respostas rápidas nas concentrações dos parâmetros avaliados.

Outro fator possível de alterar as concentrações dos parâmetros estudados, é a precipitação ocorrida na região dos pontos de coleta de água, que está diretamente ligada à maior diluição do efluente recebido pelo Córrego Jurubatuba, em razão do aumento da vazão do corpo hídrico, gerando uma eventual redução na concentração dos parâmetros estudados. No caso deste estudo, a influência da precipitação pluvial não deve ser considerada na avaliação da qualidade da água e do efluente já que, na maioria dos dias de coleta, não houve precipitações efetivas na região de amostragem.

A Tabela 2 apresenta os resultados das análises de variância realizadas para os parâmetros estudados e testes de comparação de médias pelo teste de $\mathrm{F}$ a $5 \%$ de probabilidade.

\section{Oxigênio dissolvido}

Apenas alguns valores obtidos para oxigênio dissolvido (OD) em P1 se mantiveram abaixo de 5,0 $\mathrm{mg} \mathrm{L}^{-1}$ (Figura 4A), porém Brasil (2005), não regulamenta limite mínimo de OD para efluentes e, sim, apenas para corpos hídricos. Nos pontos de coleta do córrego nenhuma avaliação de OD apresentou valores inferiores aos recomendados para corpos hídricos classe 2, na qual se inclui o Córrego Jurubatuba.

A análise de variância não mostrou diferenças significativas para a concentração de OD (teste de F, Tabela 2). Os valores encontrados foram levemente superiores ao limite mínimo de OD estabelecido em Brasil (2005). O oxigênio dissolvido não é apenas essencial para os organismos aeróbios, mas também o principal parâmetro de caracterização dos efeitos da poluição das águas por despejos orgânicos. Durante a estabilização da matéria orgânica as bactérias utilizam oxigênio em seus processos respiratórios, podendo reduzir sua concentração nos esgotos tratados ou em cursos d'água (Sperling, 2005).

Em comparação com o valor de OD encontrado em P1, Reidel et al. (2005), obtiveram valor bastante inferior $\left(1,35 \mathrm{mg} \mathrm{L}^{-1}\right) \mathrm{em}$
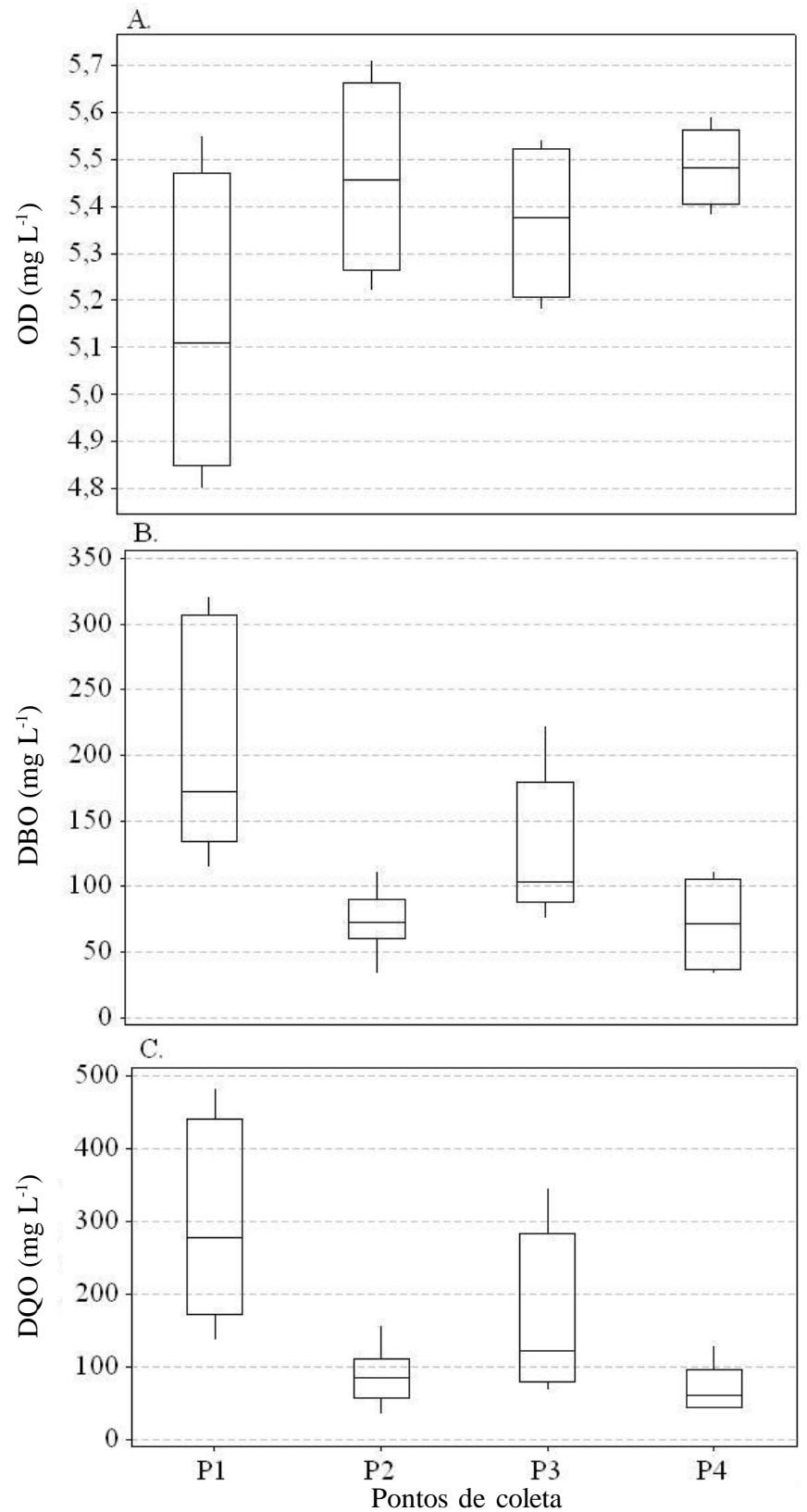

Figura 4. Box-plot das concentrações de (A) oxigênio dissolvido - OD, (B) demanda bioquímica de oxigênio - DBO, (C) demanda química de oxigênio-DQ O , obtidas para os pontos P1 (descarga do efluente tratado), P2 (50 m à montante do ponto de descarga), P3 (50 m à jusante do ponto de descarga) e P4 (120 m àjusante do ponto de descarga) 
efluentes de aves e suínos tratados em sistema de lagoas de estabilização com lagoa de polimento. No mesmo trabalho os autores obtiveram acréscimo até a concentração de 5,65 $\mathrm{mg} \mathrm{L}^{-1}$ após tratamento adicional do efluente em tanque de macrófitas com tempo de detenção de dez dias.

Toledo \& Nicolella (2002), estudaram o índice de qualidade de água de uma microbacia de uso agrícola e urbano em Guaíra, SP, obtiveram valores inferiores de OD em comparação com os obtidos nos pontos de coleta no Córrego Jurubatuba, deste estudo.

Sardinha et al. (2008) avaliaram a qualidade da água do Ribeirão do Meio, em Leme, SP, encontrando maiores valores de OD em um ponto de coleta localizado antes da cidade (média de $6,5 \mathrm{mg} \mathrm{L}^{-1}$ ) e valores menores em um ponto após a cidade (média de 1,5 $\mathrm{mg} \mathrm{L}^{-1}$ ). Os valores encontrados após a passagem do ribeirão pela cidade foram bem inferiores aos encontrados no ponto $\mathrm{P} 3$ deste estudo, fato que pode ser atribuído à decomposição de matéria orgânica (por oxidação) oriunda dos efluentes domésticos da cidade de Leme.

\section{Demanda bioquímica de oxigênio}

O gráfico de box-plot para a demanda bioquímica de oxigênio (DBO) mostra grande variação dos valores na água em todos os pontos de coleta (Figura 4B). Os pontos P1 e P3 apresentaram valores de DBO superiores e as maiores variações nesses valores, devido à variabilidade do fluxo diário de abate (Figura 3) tal como ao aumento significativo da DBO em P3, causado pelo despejo em P1 (Tabela 2).

A DBO média do efluente tratado foi igual à obtida em P3 e maior que nos pontos P2 e P4 (Tabela 2), indicando que após $50 \mathrm{~m}$ adiante do ponto de lançamento do efluente não há queda significativa no valor de DBO, e que a autodepuração, neste trecho, é insuficiente.

Os resultados de DBO para os pontos P2, P3 e P4 não atendem ao padrão para corpos hídricos classe 2 (Brasil, 2005), sendo muito superiores a este. A alta $\mathrm{DBO}$ à montante do ponto de lançamento do efluente da indústria frigorífica mostra a possibilidade da existência de despejos domésticos e/ou industriais no córrego, o que pode ser explicado pelo fato da bacia hidrográfica à qual o Córrego Jurubatuba pertence possuir uso urbano e rural (Santos \& Lopes, 2007).

Baumgartner et al. (2007), em efluente de suinocultura tratado por lagoas de estabilização e José et al. (2009), aplicando efluente de abatedouro bovino tratado em lagoas de estabilização na cultura do milho, obtiveram concentrações de DBO média de 987 e $641 \mathrm{mg} \mathrm{L}^{-1}$, respectivamente, valores bem superiores aos encontrados em P1.

Investigando a qualidade das águas do Rio Paraibuna no trecho urbano de Juiz de Fora, MG, Machado et al. (2005) obtiveram o valor de $15,57 \mathrm{mg} \mathrm{L}^{-1}$ para DBO no ponto mais crítico de seu estudo. Este resultado está bem abaixo do obtido em P2, 50 metros à montante do lançamento do efluente de abate bovino. O Córrego Jurubatuba apresenta baixa vazão, porém, se nota redução de $55,5 \mathrm{mg} \mathrm{L}^{-1}$ na concentração de DBO em $70 \mathrm{~m}$ de extensão, entre os pontos P3 e P4.

\section{Demanda química de oxigênio}

Observa-se, na Figura 4C, que o ponto P1 apresentou o maior valor de DQO entre todos os pontos analisados e a maior variabilidade de valores, principalmente decorrente da sazonalidade dos abates no frigorífico (Figura 3). O ponto $\mathrm{P} 4$ apresentou as menores média (Tabela 2) e mediana (Figura 4C) dentre os pontos avaliados.

Mesmo sem ter seu valor regulamentado pela Resolução 357/2005 do CONAMA (Brasil, 2005), a DQO é um parâmetro de grande importância em estudos sobre a qualidade da água; é um teste rápido que dá uma indicação do oxigênio requerido para estabilização da matéria orgânica. Observa-se que a DQO encontrada no ponto de despejo do efluente tratado foi igual à encontrada em P3, $50 \mathrm{~m}$ à jusante de $\mathrm{P} 1$ e maior que nos pontos P2 e P4 (Tabela 2).

Igbinosa \& Okoh (2009), avaliaram o impacto da descarga de efluente doméstico tratado de uma ETE constituída por lagoas de estabilização em uma bacia hidrográfica de uso rural, e encontraram valores de DQO entre 34,82 e 238,00 $\mathrm{mg} \mathrm{L}^{-1}$ no efluente tratado final, que foram inferiores aos obtidos em P1.

Reidel et al. (2005), analisaram o efluente de um frigorífico de aves e suínos obtido na saída de lagoa de polimento, encontrando valores médio de DQO de 174,51 mg L-1; já José et al. (2009) aplicaram efluente de abatedouro bovino tratado em lagoas de estabilização sobre a cultura do milho e obtiveram concentração média de 789,0 $\mathrm{mg} \mathrm{L}^{-1}$ de DQO, superior à do presente em P1, ressaltando a grande quantidade de matéria orgânica presente em águas residuárias de abate bovino.

As relações DQO/DBO encontradas foram: 1,54 em P1; 1,22 em P2; 1,37 para P3; e em P4, 1,05. As relações DQO/DBO em todos os pontos são consideradas baixas (von Sperling, 2005), mostrando que a fração biodegradável é elevada e há uma grande carga orgânica gerada pelo efluente, que também está presente no Córrego Jurubatuba; entretanto, a relação DQO/ DBO encontrada em P1 mostra indícios de problemas no sistema de tratamento, pois a tendência é que haja aumento desta relação ao final do tratamento biológico devido à redução da fração biodegradável, ao passo que a fração de matéria orgânica inerte (também oxidada no teste de DQO) deve permanecer praticamente inalterada. O resultado obtido para P4 indica grande presença de esgoto biodegradável, característica de lançamentos domésticos, já que a relação é praticamente igual a 1,0 .

\section{Amônia}

As concentrações de amônia apresentaram grande variação em P1 e P3. No gráfico box-plot P2 e P4 apresentaram pontos outliers, ou seja, com grande discrepância de valores em relação às outras quantidades obtidas (Figura $5 \mathrm{~A}$ ). No processo de nitrificação em cursos d'água ou estações de tratamento, a amônia é oxidada a nitrito e este a nitrato. Em sua forma livre, a amônia é diretamente tóxica aos peixes (Sperling, 2005).

Todos os pontos analisados apresentaram, em média, a mesma concentração de amônia, porém se pode notar tendência de elevação após a mistura do efluente no corpo d'água e tendência à redução após o ponto P3 (Tabela 2).

Brasil (2005), estabelece como padrão de qualidade de corpos hídricos classe 2, uma concentração máxima de $5,6 \mathrm{mg} \mathrm{L}^{-1}$ de nitrogênio amoniacal $\left(\mathrm{N}_{-} \mathrm{NH}_{4}\right)$ em faixa de $\mathrm{pH}$ entre 7,5 e 8,0; e não mais que $20 \mathrm{mg} \mathrm{L}^{-1}$ para lançamento de efluentes. Tais condições estiveram presentes nos pontos avaliados. 

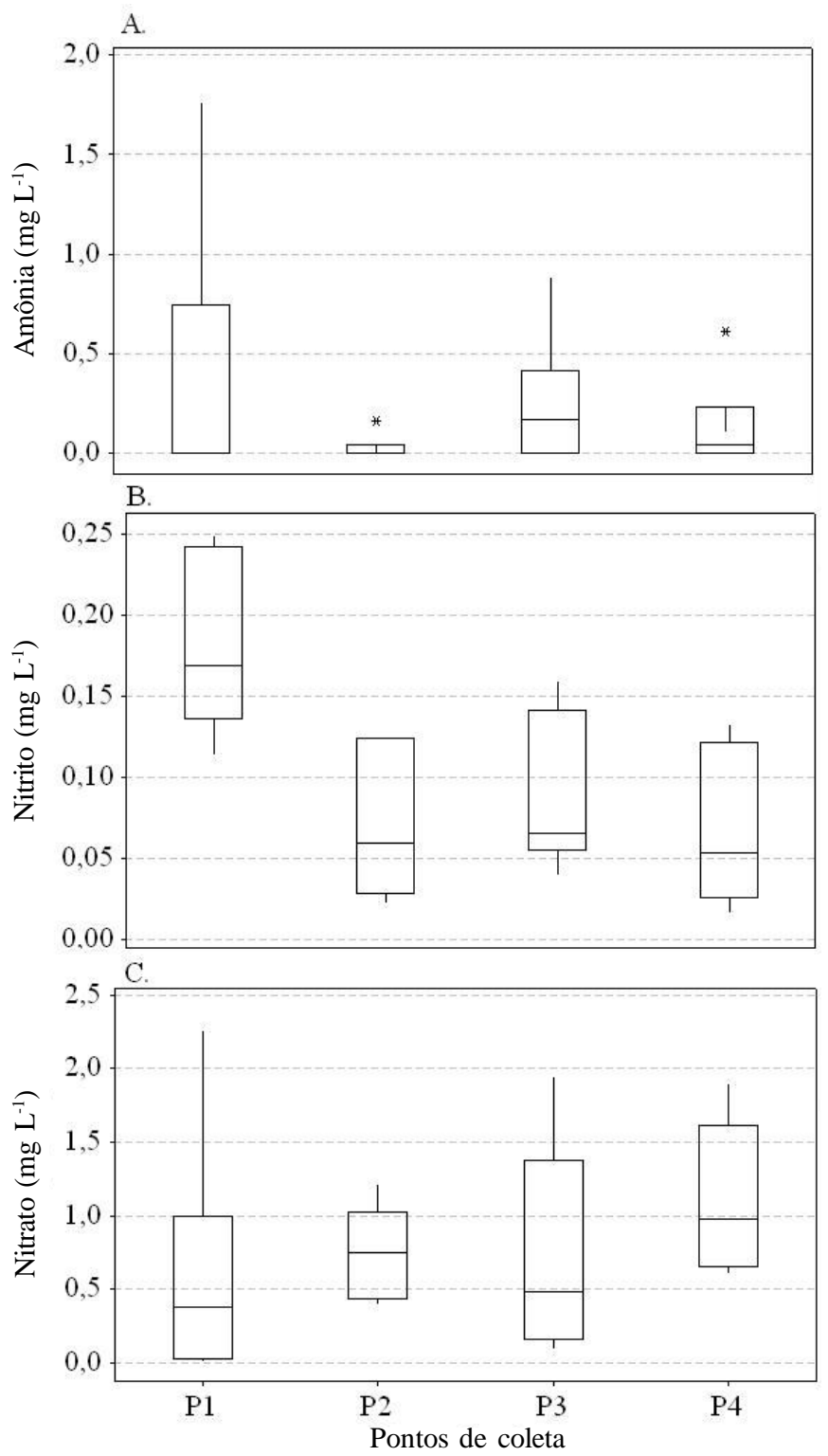

Figura 5. Box-plot das concentrações de (A) amônia, (B) nitrito, (C) nitrato obtidas para os pontos $\mathrm{P} 1$ (descarga do efluente tratado), P2 (50 m à montante do ponto de descarga), P3 (50 m à jusante do ponto de descarga) e P4 (120 m à jusante do ponto de descarga)

O valor médio encontrado de amônia em P1 foi inferior ao avaliado por Sousa et al. (2009), que analisaram o efluente final da estação de tratamento de esgotos domésticos da cidade de Aquiraz, CE, composta de quatro lagoas de estabilização em série (uma anaeróbia, uma facultativa e duas de maturação), com valor de $8,24 \mathrm{mg} \mathrm{L}^{-1}$; entretanto, o valor foi superior ao encontrado por Emongor \& Ramolemana (2004), que irrigaram culturas hortícolas e frutíferas com efluente tratado por lodos ativados e lagoas de maturação, o qual apresentava uma concentração média de nitrogênio amoniacal igual a $0,16 \mathrm{mg} \mathrm{L}^{-1}$.

\section{Nitrito}

A variabilidade das concentrações de nitrito obtidas é mostrada na Figura 5B, sendo que os intervalos de dados em cada ponto se comportaram de forma mais uniforme que ao obtido para amônia. O maior intervalo entre as concentrações máxima e mínima analisadas foi $0,135 \mathrm{mg} \mathrm{L}^{-1} \mathrm{em} \mathrm{P1}$. Este ponto também apresentou o maior intervalo interquartil.

Avaliando-se a média dos resultados obtidos (Tabela 2), a concentração de nitrito em P1 foi superior à dos demais pontos, mostrando não haver interferência do efluente tratado sobre a qualidade da água do Córrego Jurubatuba para este parâmetro. A resolução n. 357/2005 do CONAMA (Brasil, 2005), não dispõe de padrão de lançamento de efluentes para nitrito; para a qualidade de corpos hídricos classe 2, os pontos de dois a quatro atenderam à legislação (concentração máxima permitida de $\left.1,0 \mathrm{mg} \mathrm{L}^{-1}\right)$.

Gomes et al. (2009), estudaram o aporte de nutrientes e o estado nutricional da cana-de-açúcar irrigada com efluente doméstico tratado em uma ETE constituída de lagoas de estabilização no sistema australiano, obtendo valor médio de $0,02 \mathrm{mg} \mathrm{L}^{-1}$, muito inferior, porém, ao apurado em P1.

Odjadjare \& Okoh (2010), avaliaram a qualidade físicoquímica de efluente urbano tratado por lagoas de estabilização e seu impacto em um corpo hídrico receptor, encontrando médias de 0,89 e $0,27 \mathrm{mg} \mathrm{L}^{-1}$ de nitrato no efluente e a ponto 500 $\mathrm{m}$ abaixo do ponto de descarga, respectivamente; ambos os valores foram superiores aos avaliados em P1 e P3.

\section{Nitrato}

A forma mais oxidada e menos prejudicial em que se pode encontrar o nitrogênio em corpos d'água, é o nitrato. Segundo Brasil (2005), em corpos hídricos classe 2, a concentração máxima de nitrato deve ser de $10,0 \mathrm{mg} \mathrm{L}^{-1}$, padrão este foi atendido em P2, P3 e P4 (Tabela 2 e Figura 5C).

$\mathrm{O}$ comportamento geral dos valores de nitrato foi bem similar ao do nitrito, ocorrendo maior variação de amplitude de valores em P1 (Figura 5C).

A análise de variância para nitrato não mostrou diferenças significativas (teste $\mathrm{F}$ a $5 \%$ de probabilidade) não havendo, portanto, diferença entre os valores obtidos no efluente tratado e nos diversos pontos do Córrego Jurubatuba (Tabela 2).

Duarte et al. (2008), avaliaram o efeito no solo de efluente doméstico tratado e posteriormente filtrado por filtros de areia e de discos, e obtiveram a concentração de $1,95 \mathrm{mg} \mathrm{L}^{-1}$. Tal concentração foi superior à avaliada em $\mathrm{P} 1$, indicando baixa capacidade de nitrificação do sistema de tratamento que foi utilizado, já que estes autores também obtiveram concentração de nitrogênio amoniacal superior à de nitrato, fato não observado no efluente do frigorífico.

Baumgartner et al. (2007), obtiveram, em avaliação de água residuária de uma lagoa de estabilização de dejeto suíno, concentração de nitrato $\left(0,08 \mathrm{mg} \mathrm{L}^{-1}\right)$ superior aos valores em P1. Toledo \& Nicolella (2002), investigaram o índice de qualidade de água em bacia hidrográfica sob uso agrícola e urbano encontraram uma média de nitrato $\left(0,114 \mathrm{mg} \mathrm{L}^{-1}\right)$ inferior às médias encontradas em P2, P3 e P4 (Tabela 2), o que mostra maior capacidade de nitrificação do corpo hídrico no trecho avaliado por esses autores em comparação com o trecho avaliado do Córrego Jurubatuba.

\section{CONClusões}

1. Em todos os pontos analisados no Córrego Jurubatuba, os valores de DBO foram superiores aos padrões da Resolução do CONAMA n ${ }^{\circ} 357 / 2005$ para a classe. 
2. O lançamento de efluente de abate de bovinos no Córrego Jurubatuba elevou os valores de DBO e DQO no ponto P3, mas no ponto $\mathrm{P} 4$ os valores foram semelhantes aos obtidos antes do lançamento de efluente (P2).

3. As concentrações de oxigênio dissolvido, amônia, nitrito e nitrato não sofreram alterações significativas no córrego, atendendo aos padrões da resolução do CONAMA.

\section{AgradeCimentos}

Ao CNPq, pela concessão de auxílio financeiro em prol da realização desta pesquisa.

\section{LiTERATURA CITADA}

Aguilar, M. I. Nutrient removal and sludge production in the coagulation-flocculation process. Water Research, v.36, p.2910-2919, 2002.

APHA - American Public Health Association. Standard methods for examination of water and wastewater. 19.ed. Washinton: American Public Health Association, 1995. $1193 p$.

Baumgartner, D.; Sampaio, S. C.; Silva, T. R.; Teo, C. R. P. A.; Boas, M. A. V. Reúso de águas residuárias da piscicultura e da suinocultura na irrigação da cultura da alface. Engenharia Agrícola, v.27, p.152-163, 2007.

Brasil. Ministério do meio Ambiente. Conselho Nacional do meio Ambiente. Resolução n. 357. Diário Oficial da União, 17 Mar. 2005.

Duarte, A. S.; Airoldi, R. P. S.; Folegatti, M. V.; Botrel, T. A.; Soares, T. M. Efeitos da aplicação de efluente tratado no solo: pH, matéria orgânica, fósforo e potássio. Revista Brasileira de Engenharia Agrícola e Ambiental, v.12, p.302310, 2008.

Emongor, V. E.; Ramolemana, G. M. Treated sewage effluent (water) potential to be used for horticultural production in Botswana. Physics and Chemistry of the Earth, v.29, p.11011108, 2004.

Fries, J. Análisis de trazas. Métodos fotométricos comprobados. Darmstadt: Merck, 1971. 130p.

Fries, J.; Getrost, H. Organic reagents for trace analysis. Darmstadt: Merck, 1977. 236p.

Gomes, T. M.; Melfi, A. J.; Montes, C. R.; Silva, E.; Sundefeld Júnior, G. C.; Deon, M. D.; Piveli, R. P. Aporte de nutrientes e estado nutricional da cana-de-açúcar irrigada com efluente de estação de tratamento de esgoto com e sem desinfecção. Revista DAE, n.180, p.19-25, 2009.

$\mathrm{Hu}, \mathrm{B}$. New strategies for environmental water analysis. In: Proceedings of the International Conference and Exhibition on Water and the Environment, 2009, Stellenbosch. Proceedings... Stellenbosch: 2009. CD-Rom

Igbinosa, E. O.; Okoh. A. I. Impact of discharge wastewater effluents on the physico-chemical qualities of a receiving watershed in a typical rural community. International Journal of Environmental Science and Technology, v.6, p.175-182, 2009.
José, J. V.; Ribas, M. M. F.; Freitas, P. S. L.; Francisconi Júnior, J. P. Efeito da aplicação de efluente de abatedouro bovino tratado em lagoas de estabilização no solo e no desenvolvimento do milho. Pesquisa Aplicada \& Agrotecnologia, v.2, p.51-59, 2009.

Leite, V. D.; Athayde Júnior, G. B.; Sousa, J. T.; Lopes, W. S.; Prasad, S.; Silva, S. A. Tratamento de águas residuárias em lagoas de estabilização para aplicação na fertirrigação. Revista Brasileira de Engenharia Agrícola e Ambiental, v.9, p.71-75, 2005.

Machado, P. J. O.; Valle, G. M.; Rinco, L.; Carmo, L. F. Z.; Latuf, M. O. Qualidade das águas do Rio Paraibuna no trecho urbano de Juiz de Fora/MG. Revista Virtú, v.1, p.43-57, 2005.

Mees, J. B. R.; Gomes, S. D.; Vilas Boas, M. A.; Fazolo, A.; Sampaio, S. C. Removal of organic matter and nutrients from slaughterhouse wastewater by using Eichhornia crassipes and evaluation of the generated biomass composting. Engenharia Agrícola, v.29, p.466-473, 2009.

Merck. The testing of water. 9.ed., Darmstadt: Merck, 1972. 224p.

Morrison, G.; Fatoki, O. S.; Persson, L.; Ekberg, A. Assessment of the impact of point source pollution from the Keiskammahoek Sewage Treatment Plant on the Keiskamma River - pH, electrical conductivity, oxygen demanding substance (COD) and nutrients. Water SA., v.27, p.475-480, 2001.

Naime, R.; Garcia, A. C. Utilização de enraizadas no tratamento de efluentes agroindustriais. Estudos Tecnológicos, v.1, p.9$20,2005$.

Odjadjare, E.; Okoh, A. Physicochemical quality of an urban municipal wastewater effluent and its impact on the receiving environment. Environmental Monitoring and Assessment, v.170, p.383-394, 2010.

Pacheco, J. A. S.; Wolff, D. B. Tratamento dos efluentes de um frigorífico por sistema australiano de lagoas de estabilização. Disc. Scientia. Série: Ciências Naturais e Tecnológicas, v.5, p.67-85, 2004.

Reidel, A.; Damasceno, S.; Zenatti, D. C.; Sampaio, S. C.; Feiden, A. Queiroz, M. M. F. Utilização de efluente de frigorífico, tratado com macrófita aquática, no cultivo de tilápia do Nilo. Revista Brasileira de Engenharia Agrícola e Ambiental, v.9, p.181-185, 2005.

Rodrigues, L. S.; Silva, I. J.; Santos, R. L. H.; Goulart, D. B.; Oliveira, P. R.; von Sperling, M.; Fontes D. O. Avaliação de desempenho de lagoa de polimento para pós-tratamento de reator anaeróbio de manta de lodo (UASB) no tratamento de águas residuárias de suinocultura. Arquivo Brasileiro de Medicina Veterinária e Zootecnia, v.61, p.1428-1433, 2009.

Rodrigues, L. S.; Silva, I. J.; Zocrato, M. C. O.; Papa, D. N.; von Sperling, M.; Oliveira, P. R. Avaliação de desempenho de reator UASB no tratamento de águas residuárias de suinocultura. Revista Brasileira de Engenharia Agrícola e Ambiental, v.14, p.848-856, 2010.

Santos, L. R.; Lopes, L. M. Bacia do Córrego da Lagoinha em Anápolis (GO): Morfopedologia, uso da terra e problemas decorrentes. In: Simpósio Brasileiro de Geografia, 13, 2007 , Viçosa. Anais... Viçosa: UFV, 2007. CD-Rom 
Sardinha, D. S.; Conceição, F. T.; Souza, A. D. G.; Silveira, A.; Julio, M.; Gonçalves, J. C. S. I. Avaliação da qualidade da água e autodepuração do ribeirão do meio, Leme (SP). Engenharia Sanitária e Ambiental, v.13, p.329-338, 2008.

Sousa, C. C. M.; Bezerra, F. M. L.; Mota, S.; Aquino, B. F. Avaliação química-bromatológica e produtiva do capim Tifton 85 (Cynodon sp.) irrigado com esgoto doméstico tratado. Revista DAE, p.26-32, 2009.
Sousa, J. T.; Ceballos, B. S. O.; Henrique, I. N.; Dantas, P. D.; Lima, S. M. S. Reúso de água residuária na produção de pimentão (Capsicum annuum L.). Revista Brasileira de Engenharia Agrícola e Ambiental, v.10, p.89-96, 2006.

Toledo, L. G.; Nicolella, G. Índice de qualidade de água em microbacia sob uso agrícola e urbano. Scientia Agricola, v.59, p.181-186, 2002.

von Sperling, M. Introdução à qualidade das águas e ao tratamento de esgotos. 3.ed., Belo Horizonte: DESA/UFMG 2005.452p. 